\title{
Ayak ve ayak bileğinin travmatik çıkıkları
}

\author{
Dislocations of the foot and ankle
}

\author{
Kaan Süleyman Irgıt ${ }^{1}$, Tolga Onay ${ }^{2}$ \\ ${ }^{1}$ Marmara Üniversitesi Tıp Fakültesi Ortopedi ve Travmatoloji Anabilim Dalı, İstanbul \\ ${ }^{2}$ Marmara Üniversitesi Pendik Eğitim ve Araştırma Hastanesi Ortopedi ve Travmatoloji Kliniği, İstanbul
}

\begin{abstract}
Ayak ve ayak bileği vücutta en fazla kemik ve eklemin bulunduğu bölgedir. Ayak ve ayak bileğinde kırıklar daha sık görülmekte olup, izole çıkıklar oldukça nadirdir. Tibiotalar ve subtalar eklemlerin çıkıklarına kolayca tanı konabilirken, ayak ortası ve önündeki eklem çıkıkları sıklıkla gözden kaçabilmektedir. Hastalarda iyi fonksiyonel sonuç elde edebilmek için, tanıyı erken koyarak ve doğru tedaviyle, stabil ve anatomik redüksiyon elde etmek esastır. Bu derlemenin amacı, izole ayak ve ayak bileği çıkıklarının görülme sıklığı, oluş mekanizmaları, tedavi ve sonuçları üzerinde durmaktır.
\end{abstract}

Anahtar sözcükler: ayak bileği; ayak; çıkık
The foot and ankle is the region where most of the bones and joints are located in the body. Foot and ankle fractures are more frequent and isolated dislocations are very rare. The dislocations of the tibiotalar and subtalar joints can be easily diagnosed, whereas the mid- and forefoot joint dislocations are often overlooked. Early diagnosis and obtaining a stable joint with anatomic reduction with proper treatment is essential for good functional results. The aim of this review is to focus on the incidence, mechanisms, treatment, and outcomes of isolated foot and ankle dislocations.

Key words: ankle; foot; dislocation

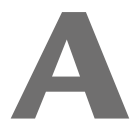

yak ve ayak bileği vücutta en fazla kemik ve eklemin bulunduğu bölgedir. Ayak ve ayak bileği yaralanmaları spor yaralanmaları ve trafik kazaları başta olmak üzere, meslek kazalarında ve günlük pratikte de oldukça sık görülmektedir. Eklem ve kemik sayısına oranla kırıklı çıkıklar ve kırıklar sık görülmekle birlikte, ayak ve ayak bileğinde izole çıkıklar oldukça nadirdir. Kırıklı çıkıklar eklemde daha ciddi hasarlara yol açmakta, ancak izole çıkıklar genellikle eklemde daha az hasara neden olurken, komplikasyonları da daha nadir olmaktadır. Bu derlemenin amacı, izole ayak ve ayak bileği çıkıklarının görülme sıklığı, oluş mekanizmaları, tedavi ve sonuçları üzerinde durmaktır.

\section{TiBiOTALAR (AYAK BILEĞi) ÇIKIKLARI}

Ayak bileği kırıklı çıkıkları oldukça sık görülen yaralanmalar olmasına rağmen, ayak bileği çıkıkları son derece nadir yaralanmalardır. Wight ve ark.'nın yaptığı bir sistematik derlemede, izole ayak bileği çıkıklarının (IABÇ) oranı beş milyonda 1-4'tür. ${ }^{[1]} \mathrm{I} A B C ̧$, kırı̆̆ın eşlik etmediği izole kapsül ve bağ yaralanmaları neticesinde oluşur. En sık postero-mediyal çıkık görülür. IABÇ ile ilgili literatürde, genellikle sadece olgu sunumları mevcuttur; geniş seriler yer almamaktadır.

\section{Mekanizma-Epidemiyoloji}

Oldukça nadir gözüken bu yaralanmalar, 1995 yılına kadar literatürde sadece 95 adet bildirilmiştir. ${ }^{[2]}$ Spor yaralanmaları en sık etiyolojik neden olarak karşımıza çıkmaktadır. Wight ve ark., IABÇ ile ilgili 2017 yılında güncel bir derleme yapmışlar, literatürdeki olgu sunumu şeklindeki 154 olguyu derlemişlerdir. ${ }^{[1]}$ Bu rapora göre; yaralanmaların \%31'i spor yaralanmaları, \%26'sı yüksek enerjili diğer yaralanmalar, \%23'ü araba kazası, \%11'i motosiklet kazası iken, \%5'i düşük enerji mekanizmaları ile meydana gelmektedir. Yaralanmaların yarısı açık yarısı ise kapalı yaralanma şeklinde görülmektedir. Hastaların ortalama yaşı 29'dur. Tahmin edilebileceği gibi, yüksek enerjili yaralanmalarda açık yaralanma görülme olasılığı, kapalılara oranla daha fazladır.

- Illetişim adresi: Doç. Dr. Kaan Süleyman Irgıt, Fevzi Çakmak Mah Muhsin Yazıcıoğlu Cad. No:10 Üst Kaynarca, Pendik, İstanbul Tel: 0532 - 4466768 e-posta: kaanirgit@yahoo.com

- Geliş tarihi: 9 Kasım $2018 \quad$ Kabul tarihi: 9 Kasım 2018 
Çıkık yönü incelendiğinde postero-mediyal çıkıklar (\%46) ilk sırayı almaktadır. Bunu sırasıyla mediyal, poterior ve lateral çıkıklar izlemektedir.

Postero-mediyal çıkıklar, ayak maksimum plantar fleksiyonda iken ayak bileğinin inversiyona zorlanması ve aksiyel yüklenme ile meydana gelir. ${ }^{[3]}$ Ayak bileğinin en instabil durumu maksimum plantarfleksiyon halidir, çünkü talusun en dar olan kısmı mortis içinde kalmaktadır. Bu pozisyonda, posterior talofibular bağ hariç talusun tüm bağ yapıları ve ön kapsülü gerilir. Eğer bu pozisyonda yeterli bir inversiyon güç uygulanırsa, sırasıyla ön kapsül, anterior talofibular bağ (ATFL), kalkaneofibular bağ (CFL) yırtılır. Ancak deltoid bağ sağlam kalacaktır.

Alami ve ark., sindezmozun parçalandığı ve talusun yukarı doğru çıktığı tibia ve fibulayı ikiye ayıran bir çıkık tipi de tarif etmişlerdir. ${ }^{[4]}$ Yukarı doğru olan çıkıkların muhtemel mekanizması diğerlerinden farklıdır ve aşııı dorsifleksiyonda olan ayak bileğinin lateral rotasyon ve pronasyona gitmesi ile tibiofibular sindezmozu parçaladığı düşünülmektedir. ${ }^{[4]}$

\section{Klinik-Tanı}

Hastalar acil servislere genellikle belirgin bir deformite ve ağrı ile başvurduklarından dolayı, tanı koymak zor değildir. Uygun çekilmiş röntgenler ile çıkık yönü tespit edilebilir. Birlikte olan diğer yaralanmalar için manyetik rezonans (MR) görüntüleme, bilgisayarlı tomografi (BT) ve anjiyografiden yararlanılabilir. Özellikle cerrahi redüksiyon esnasında artroskopik girişim yapılmadıysa, sonrasında MR ile kondral hasar varlığı incelenebilir. Redüksiyon sonrası ağrısı devam eden hastalarda mutlaka MR incelemesi yapılmalıdır.

\section{Tedavi}

Çoğu yazar, kapalı çıkıklar için acil şartlarda uygun bir sedasyon ve kas gevşemesi ile kapalı redüksiyon ve 6-8 hafta alçı önermektedir. Eğer erken anatomik redüksiyon sağlanmaz ise nörovasküler hasar riski artar. ${ }^{[5]}$ Kapalı çıkıklarda redüksiyon esnasında eşlik eden kondral lezyonları tespit etmek için artroskopi de uygulanabilir. Kondral lezyon tespit edilirse, emilebilen vida ve çiviler ile mümkünse tespit edilmelidir. ilk redüksiyon esnasında bağ tamiri yapılması tartışmalıdır. ${ }^{[6]}$

Deltoid bağ tamiri, mediyal malleol hipoplazisi varlığında veya redüksiyon sonrası stres testi yapıldığında mediyal instabilite veya redüksiyon sonrası halen mediyalde açıklık varsa önerilir. Postero-mediyal çıkıklarda deltoid bağ sağlam kaldığından, primer tamiri önerilmez. Yukarı çıkıklarda sindezmoz tamiri için ve redüksiyon için sindezmoz vidaları da konulmalıdır. ${ }^{[4]}$
Açık yaralanmalarda, standart açık kırık veya çıkıklara yaklaşımda olduğu gibi yıkama ve debridman uygulanmalıdır. Bu esnada kondral hasarların varlığı incelenmelidir. Açık yaralanmalarda tespit edilen bağ yaralanmalarının ve anterior kapsülün tamiri önerilir.[7] Geç kalınmış cerrahilerde veya redüksiyonlarda sonuçlar çok kötüdür.

\section{Sonuçlar ve Komplikasyonlar}

Olguların yaklaşık \%30'unda nörovasküler hasar görülür. Dorsalis pedis arteri, tibial sinir, süperfisiyel ve sural sinirde hasar görülebilir. Anterior tibial arter yaralanmasına bağlı bildirilmiş ampütasyon olguları vardır. ${ }^{[1]}$ Kronik derin peroneal sinir lezyonu ve parestezi de bildirilmiştir, ancak bunlar genelde zamanla düzelir. Açık yaralanmalarda nörovasküler hasar görülebilir. En sık görülen komplikasyon kondral hasar ve eklem sertliğidir.

Açık yaralanmalar sonrası derin ve yüzeyel enfeksiyon da gözlenebilir.

Kullanılan tespit yönteminin eklem sertliğine veya instabiliteye katkıda bulunmadığı gözlenmiştir.[1] Tibiotalar instabilite, dejeneratif artrit ve kapsüler kalsifikasyonlar en sık görülen geç dönem komplikasyonlardır. Çoğu hastada dorsifleksiyon, plantarfleksiyon, inversiyon ve eversiyonda kısıtlılık kalsa da bu klinik olarak anlamlı değildir. ${ }^{[8]}$ Özellikle transplantar pinleme yapılan veya açık çıkıklardan sonra, dejenerasyon görülme olasılığı daha fazladır.

Sonuç olarak; izole ayak bileği çıkıkları nadir ligamentöz yaralanmalardandır. Genelde plantarfleksiyonda aksiyel yüklenme sonucu meydana gelir. En sık spor travması veya motorlu taşıt kazası sonrası görülmektedir. Literatürde hiç risk faktörü gösterilememiştir. Eklem sertliği ve posttravmatik artroz en sık görülen komplikasyonlar arasındadır. Tedavisinde kısa dönem tespit sonrası fonksiyonel rehabilitasyon ile, genellikle uzun dönemde iyi fonksiyonel sonuçlar alınmaktadır. Bağ tamiri yapılmasa da instabilite genelde gözlenmemektedir.

\section{SUBTALAR EKLEM ÇIKIKLARI}

Subtalar çıkık talokalkaneal (subtalar) ve naviküler eklemlerin birlikte çıkması olarak tanımlanmıştır. Genellikle yüksek enerjili yaralanmalar neticesinde görülen ve izole yaralanmaları oldukça nadir olan subtalar çıkıklar, ayaktaki tüm travmatik yaralanmaların \%1'ini oluşturur. Illk olarak Dufarest ve Judey tarafindan 1811'de tanımlanmıştır. illk sınıflaması DeLee tarafından 1853 yılında yapılmış ve 1856 yılında Malgaigne ve Buerguer tarafından modifiye edilmiştir; günümüzde halen bu sınıflama kullanılmaktadır. ${ }^{[9,10]}$ 

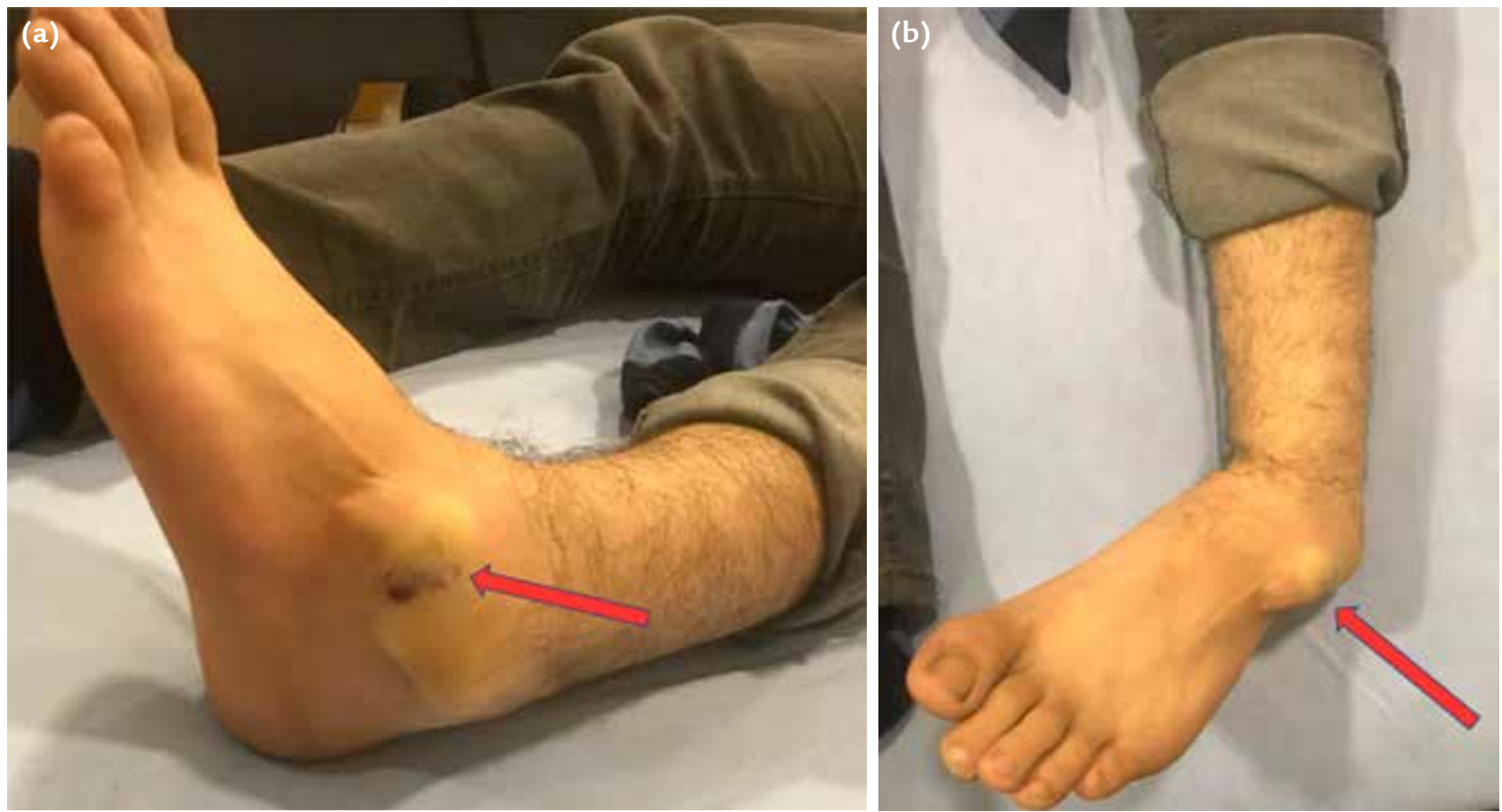

Şekil 1. a, b. Mediyal subtalar dislokasyonu olan hastanın klinik görünümü. Hastanın cildinde basıya bağlı dolaşım bozukluğunun başladığı görülmektedir (ok).

\section{Mekanizma}

En sık yüksek enerjili yaralanmalar sonrası görülür. En sık olanları mediyal dislokasyonlardır, inversiyon/ rotasyon yaralanmaları olarak görülür. Yaklaşık \%80'i mediyal dislokasyon şeklinde görülür. Lateral dislokasyonlar daha çok yüksek enerjili travma sonucudur ve \%17 civarında karşımıza çıkar. ${ }^{[11]}$ Yaralanma mekanizmaları; motorlu araç kazaları (\%38), yüksekten düşme (\%30), spor yaralanmaları (\%21) ve daha nadiren ayağın çukura girmesi veya basamak kaçırmak gibi düşük enerjili yaralanmalardır. Açık yaralanma \%25 görülürken, lateral çıkıkların açık olma ihtimali daha fazladır. Beraberinde talonaviküler çıkık, talar baş kırıkları, posterior talus kırıkları, küboid ve anterior kalkaneus kırıkları görülebilir.

\section{Epidemiyoloji}

Genç erkeklerde daha sık görülmektedir. Subtalar mediyal çıkıkların $\% 55^{\prime} \mathrm{i}$, lateral olan çıkıkların da \%72'si kırıklı olur bu nedenle izole yaralanmalar oldukça nadirdir. ${ }^{[11]}$ En sık mediyal çıkık görülürken, bunu sirasiyla lateral, posterior, anterior ve antero-lateral çıkıklar izler. Bütün bunların \%15,6'sı açık yaralanma şeklinde meydana gelir.

\section{Klinik-Tanı}

Fizik muayenede, mediyal ve lateral çıkık yönüne doğru deformiteyi tespit etmek mümkündür (Şekil 1). Anterior ve posterior çıkıklarda daha az dizilim kusuru olduğundan, bunlar daha az belirgindir. Ön-arka ve yan grafiler ile çıkığı tespit etmek mümkündür (Şekil 2). Talonaviküler çıkık veya kırıklı çıkıkların bu patolojiye eşlik edebileceği unutulmamalıdır; bu nedenle hastaların redüksiyon sonrası $\mathrm{BT}$ ile incelenmesi uygun olacaktır. Plantar ekimoz önemli bir klinik bulgudur.

\section{Tedavi}

Subtalar çıkıkların erken dönemde redüksiyonu, damar, sinir ve diğer yumuşak doku yaralanmalarının önüne geçilmesi açısından çok önemlidir. Eğer süratle uygulanabilirse çoğu subtalar çıkık genel anestezi altında uygun kas gevşemesi ile kapalı redüksiyon ile oturur. ${ }^{[12]}$ Mediyal subtalar çıkıkların yaklaşık \%10'u kapalı redüksiyon ile oturmaz. Tibialis posterior veya fleksör dijitorum longus tendonu redüksiyonu engelleyebilir ve açık yaklaşım ile tendonu aradan çıkartmak gerekebilir. Bu gibi durumlarda, antero-lateral veya oblik Ollier lateral yaklaşımı kullanılabilir. Redüksiyon sonrası talar çıkıntı kırık açısından değerlendirilmelidir. 

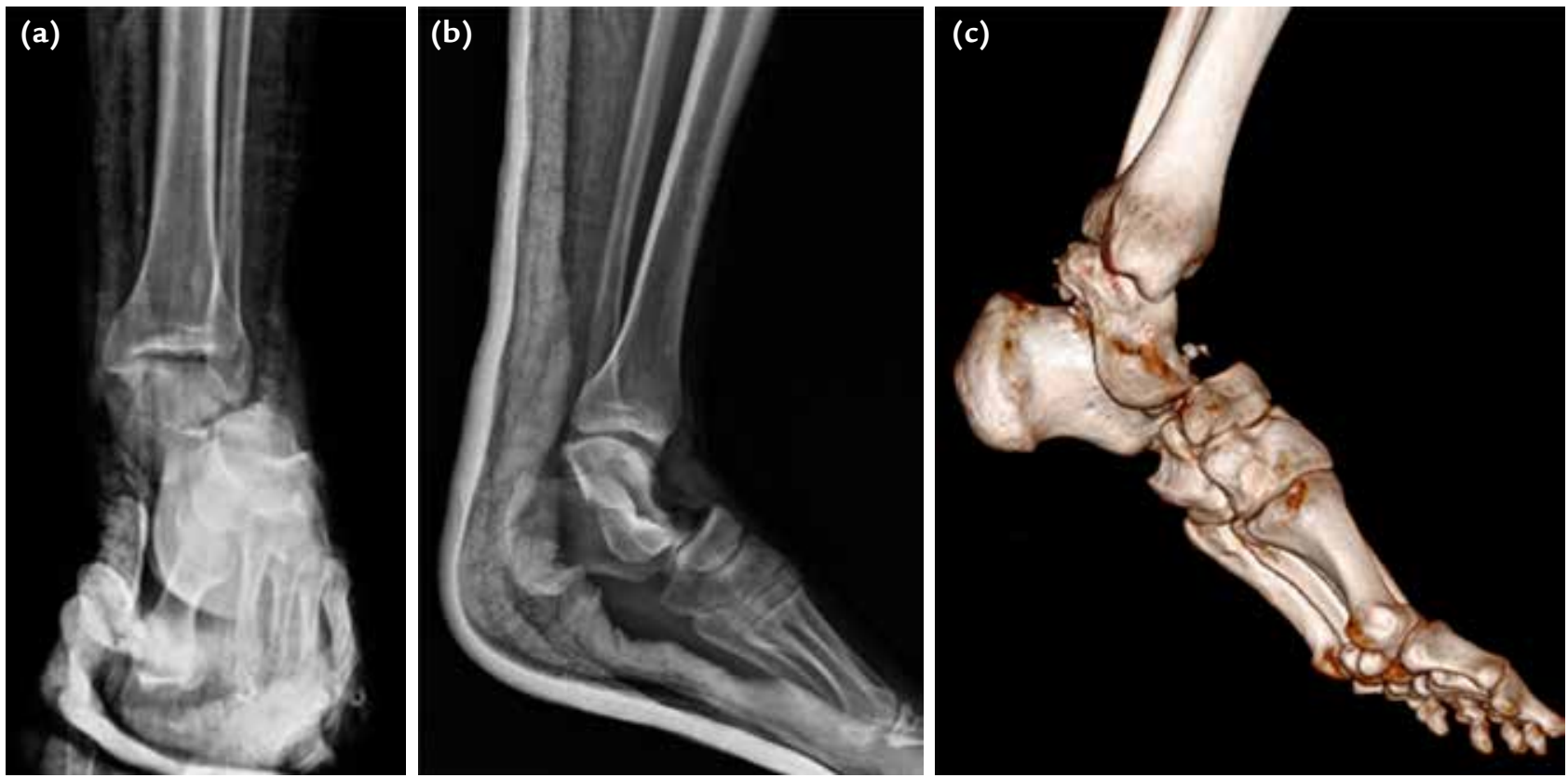

Şekil 2. a-c. Lateral subtalar dislokasyonu olan hastanın AP (a), lateral (b) ve BT (c) görüntüleri.

Öne ve arkaya olan çıkıklar, diz fleksiyonda iken aksiyel traksiyon ile redükte edilebilir. Redüksiyon sonrası 4-6 hafta alçı tespiti uygulamak ve bastırmamak gerekir.

Bazı yazarlar, redüksiyona rağmen nadiren instabilite halen devam ediyorsa, geçici Kirschner teli (K-teli) tespiti önermektedir. Pavic ve ark., K-teli ile tespit sonrası sonuçların daha iyi olduğunu ileri sürmektedirler. ${ }^{[13]}$ Yine, tespit süresi kısaldıkça sonuçların daha iyi olduğunu iddia eden yazarlar da vardır; ancak, dört haftadan daha kısa süreli tespit önerilmemektedir. ${ }^{[11]}$ Tercihe göre nadiren eksternal fiksatör de uygulanabilir.

\section{Komplikasyon}

Erken dönemde ağrı, katılık, subtalar ve ayak bileğinde hareket kaybı görülür. Geç dönemde en sık posttravmatik artroz gözlemlenir. Lateral çıkıklarda avasküler nekroz ve derin enfeksiyon da görülebilmektedir. ${ }^{[14]}$

\section{MIDTARSAL EKLEM YARALANMALARI}

"Chopart eklemi" ya da "transvers tarsal eklem" olarak da isimlendirilen midtarsal eklem, ayağın longitudinal arkına transvers olarak yerleşmiş olan ve arka ayağın pozisyonuna entegre biçimde hareket eden talonaviküler ve kalkaneoküboid eklemlerden meydana gelmiştir. Birlikte hareket etmeleri nedeniyle, bu eklemlerin izole çıkıkları nadirdir. ${ }^{[15]}$

\section{Mekanizma-Epidemiyoloji}

Talonaviküler eklem daha esnek yapıda olan mediyal kolonun bir parçası iken, kalkaneoküboid eklem daha rijid lateral kolonun parçası olup, subtalar eklemle birlikte ayağın inversiyon ve eversiyonunda fonksiyon görür.

Main ve Jowett, midtarsal yaralanmaları, yaralanmaya neden olan kuvvetin ve deplasmanın yönüne göre beş ana gruba ayırmıştır. ${ }^{[16]}$ Yaralanmalar sprain, subluksasyon ve kırığın da eşlik ettiği dislokasyon şeklinde olabilmektedir.

\section{Tedavi-Sonuçlar}

Longitudinal stres, midtarsal eklem yaralanmalarında \%40 oranında en sık görülen tiptir. Sıklıkla yüksekten düşme veya motorlu araç kazası gibi yüksek enerjili travmalarla, ayak önü plantar fleksiyonda iken metatars başlarına uygulanan aksiyel yüklenme mekanizmasılla navikulanın talus ve kuneiform kemikler arası ve küboidin metatars tabanlan ve kalkaneal önü arasında sıkışması neticesinde meydana gelir. Nondeplase yaralanmalar ayağın elevasyonu ve altı hafta dizaltı alçı immobilizasyonla tedavi edilebilir. Deplase ve instabil longitudinal midtarsal yaralanmalara sıklıkla ciddi yumuşak doku lezyonlan ve kırıklar eşlik etmekte olup, en kötü prognoza sahiptir. Bunlarda aşamalı tedavi tercih edilmesi gerekmekte olup, ilk aşamada yumuşak doku tedavisine, sonrasında kemiğe yönelik işlemler 

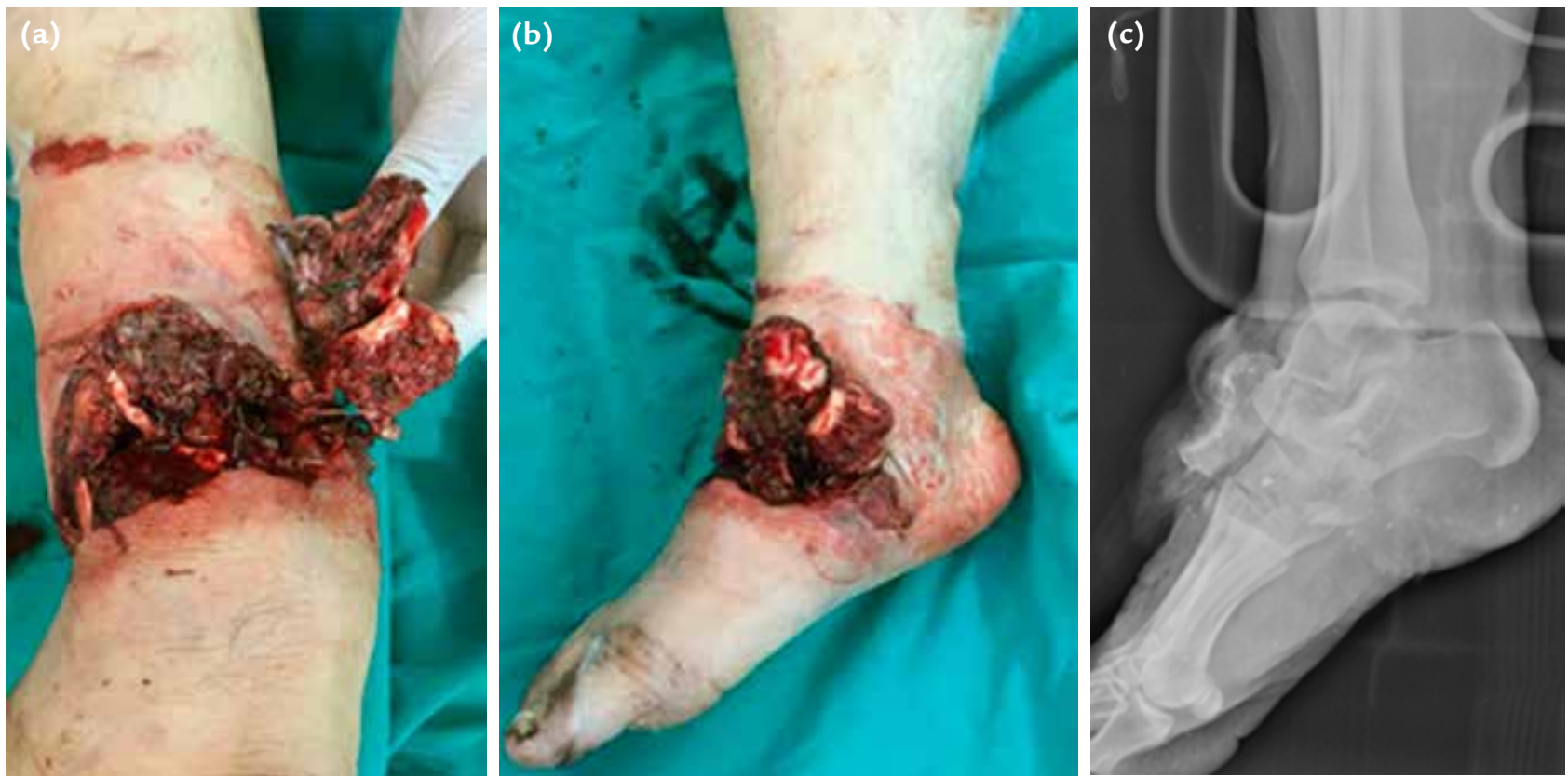

Şekil 3. a-c. Motosiklet kazası sonucu navikula ve mediyal kuneiform kemiklerin ekspoze olduğu midtarsal eklemin açık çıkığı.

yapılmalıdır. Longitudinal yaralanmalarda, ayağın uzun arkı sıklıkla hasar gördüğünden ve ayağın boyu kısaldığından, eksternal fiksatör ile uzunluğun tekrar sağlanması oldukça kullanışlı ve tercih edilen bir yöntemdir. ${ }^{[17]}$

Mediyal stres, \%30 oranı ile en sık görülen ikinci tip olup, plantar fleksiyondaki ayağın önünün inversiyonu neticesinde gelişiri. ${ }^{[18]} \mathrm{Bu}$ yaralanma aynı yönde kuwete maruz kalmaya devam ederse, talokalkaneal interosseöz bağ yırtılması ve sonrasında subtalar eklem çıkığı gelişebilir. Nondeplase yaralanmalarda altı hafta alçı ile tedavi uygulanır. Deplase çıkıklar sıklıkla kapalı olarak redükte edilebilmekte, perkütan tespit uygulanabilmektedir. Ön ayağın zorlu abduksiyonu, midtarsal eklem lateral stres yaralanmalarına neden olan mekanizmadır. Küboid kemiğin "nutcracker" kırığı bu yaralanmaya sıklıkla eşlik eder. Plantar stres, \%7'lik oranıyla en az görülen tiptir. Crush yaralamalar, bu sınıflandırmanın son tipidir. Yüksek enerjili yaralanmalarla meydana gelmiş olup, belirgin bir kırık ya da çıkık konfigürasyonu yoktur (Şekil 3). Bunlarda aşamalı tedavi tercih edilmelidir. Bazen primer ampütasyon tek tedavi tercihi olabilmektedir.

\section{LISFRANK ÇIKIKLARI}

\section{Mekanizma-Epidemiyoloji}

Tarsometatarsal (TMT) (Lisfrank) eklem kompleksi TMT, intertarsal ve proksimal intermetatarsal eklemlerden meydana gelir. Ayağın transvers ve longitudinal arkının bütünlüğünün devamı, bu eklem kompleksinin sağlam osseöz ve ligamentöz anatomisiyle sağlanabilmektedir. Lisfrank yaralanması, bir veya daha fazla sayıda metatarsın tarsal kemiklerden deplase olması olarak tanımlanmıştır (Şekil 4). Ancak bu isim, daha sıklıkla 2. TMT eklemin yaralanmaları için kullanılmaktadır. ${ }^{[19]}$ En sık tespit edilen yaralanma mekanizması, ayak yerle temas halinde iken ayağın plantar fleksiyon ve abduksiyona zorlanmasıdır. Sıklıkla kırıklı çıkık olarak görülür.

\section{Klinik-Tanı}

Tanı için klinik şüphe önemlidir. Yaralanmaların \%20'si ilk değerlendirmede gözden kaçar. ${ }^{[20]}$ Standart görüntülemede antero-posterior, lateral ve oblik grafiler elde edilmelidir. İkinci metatars tabanı ve mediyal kuneiform arasında $>2 \mathrm{~mm}$ açılma varlığı instabiliteyi düşündürür. Bunun dışında, konvansiyonel grafilerde TMT yaralanmalarında patognomonik olan "fleck sign" (leke bulgusu) saptanabilir. Şüpheli olgularda basarak çekilen ayak grafileri oldukça önemlidir. Yui-Kai ve ark., çalışmalarında, basarak çekilen grafilerde 1. ve 2. metatars tabanları arasındaki ortalama mesafeyi 2,5 mm olarak saptamış, $>3 \mathrm{~mm}$ üzeri aralığın Lisfrank yaralanmasını düşündürmesi gerektiğini belirtmişlerdir. ${ }^{[21]} \mathrm{MR}$ ve $\mathrm{BT}$ 'nin şüpheli 

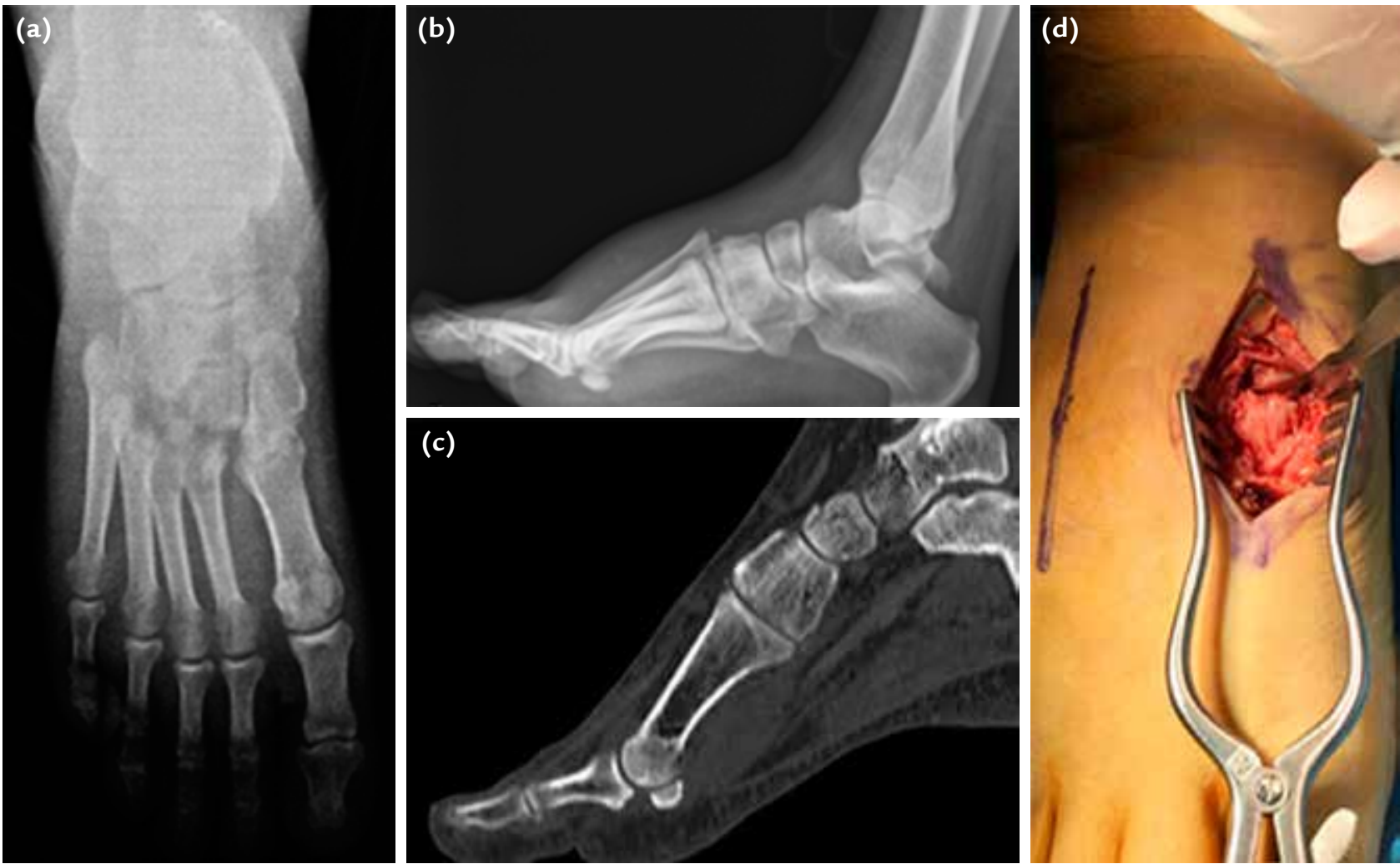

Şekil 4. a-d. Lisfrank kırıklı çıkık olan hastanın AP (a) ve lateral (b, c) grafileri. Hastanın sagittal BT kesidinde 1. metatarsı redükte gözükmesine rağmen, ameliyat sırasında (d) instabil olduğu saptanmıştır.

olguların tanısında daha duyarlı olduğu kabul edilmektedir. ${ }^{[22]}$ Bunun dışında, hastalar anestezi altında muayene edilerek ve ameliyat sırasında görüntülenerek tanı konabilmektedir. ${ }^{[23]}$

Pek çok sınıflama yapılmış olmakla birlikte, bunlardan en kabul göreni, yaralanmayı eklem bütünlüğü, etkilenen bölge ve instabilitenin yönüne göre ayıran Myerson sınıflamasıdır (Tablo 1). ${ }^{[24]}$

Tablo 1. Lisfrank eklem yaralanmalarında Myerson sınıflaması

Tip A: Eklemin total deplasmanı

Tip B: Eklem bütünlüğünde parsiyel bozulma

B1: Mediyal çıkık

B2: Lateral çıkık

Tip C: Eklemin diverjan çıkığı

C1: Parsiyel eklem deplasmanı

C2: Total eklem deplasman

\section{Tedavi-Sonuçlar}

Tedavide esas belirleyici faktör instabilite varlığıdır. Lisfrank yaralanmalarında konservatif tedavi, stabil yaralanma paterni olan veya cerrahi girişimi tolere edemeyebilecek hastalarda uygulanabilir. Altı hafta alçı veya yürüme botu ile immobilizasyon sonrası hastalara progresif olarak yük verdirilir. Ağrının geçmesi ve normal fonksiyonlara dönüş altı ayı bulabilir. ${ }^{[25]}$

Cerrahi tedavi, yumuşak dokuda ödem gelişmeden erken dönemde ya da ödem geliştiyse geriledikten sonra yapılmalıdır. Altı aydan sonra yapılan cerrahi girişimlerin sonuçları kötü olarak bulunmuştur. ${ }^{[26]}$ Mediyal ve orta kolonda stabiliteyi sağlamak için rijid tespit uygulanırken, daha mobil olan lateral kolonda K-telleri ile geçici tespit tercih edilebilir. Cerrahi yaklaşım, redüksiyon ve tespitte tercih edilmesi gereken sıralama, proksimalden distale ve mediyalden laterale doğru olmalıdır. ${ }^{[25]}$ Tespit, perkütan veya açık redüksiyonla uygulanabilir. İyi fonksiyonel sonuç elde edebilmek için stabil ve anatomik redüksiyon elde etmek esastır. 

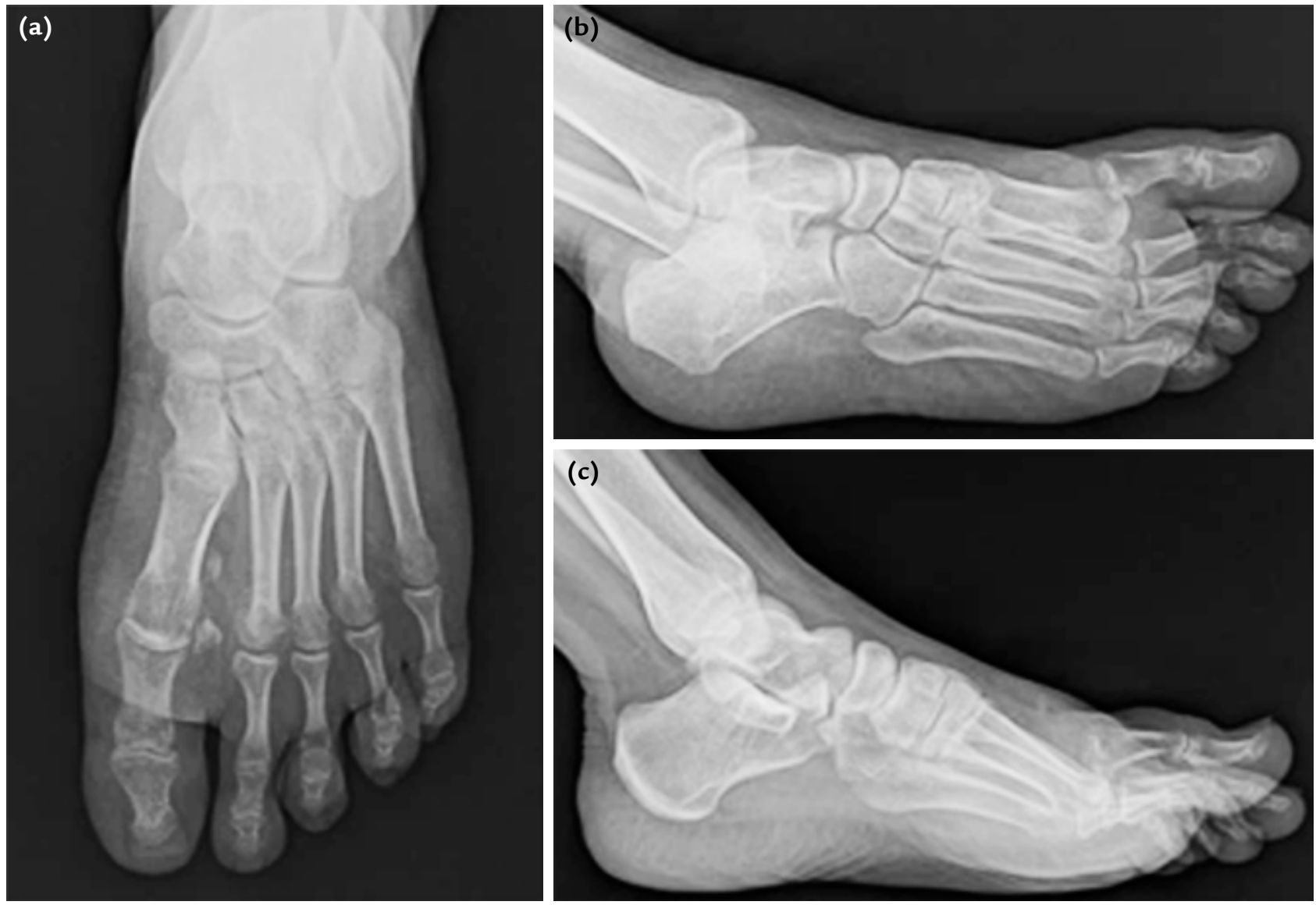

Şekil 5. a-c. Yirmi iki yaşında erkek hasta, yüksekten atlama ile ayak başparmağın dorsifleksiyona zorlanması sonucu gelişen 1 . MTF eklem dorsal çıkığına ait AP (a), lateral (b) ve oblik (c) grafileri.

\section{METATARSOFALANGEAL (MTF) VE INTERFALANGEAL (IF) EKLEM ÇIKIKLARI}

MTF çıkıkları nadir görülen yaralanmalar olup, genellikle ayağa aksiyel yüklenmeyle eklemin dorsifleksiyona zorlanması sonucu meydana gelir. Birinci MTF eklem çıkığı ile diğerlerine göre daha sık karşılaşılmakta olup, çıkığın yönü genelde dorsale olmakla birlikte, plantar ve lateral çıkıklar da görülebilir. Tanı fizik muayene ve X-ray ile rahatça konabilir (Şekil 5). MTF çıkıkları genellikle lokal anestezi altında kapalı redüksiyonla yerine getirilebilmektedir. Sesamoid kemikler veya eklem kapsülü redüksiyonu engelleyebilmekte, bu durumlarda ise açık redüksiyon gerekebilmektedir. ${ }^{[27]}$ Açık redüksiyon sonrası dört hafta süreyle bir adet K-teli ile tespit uygulanabilir (Şekil 6).

iF eklem çıkıkları oldukça nadir görülse de, bunlarda da en sık etkilenen 1. parmaktır. En sık etkilen ikinci
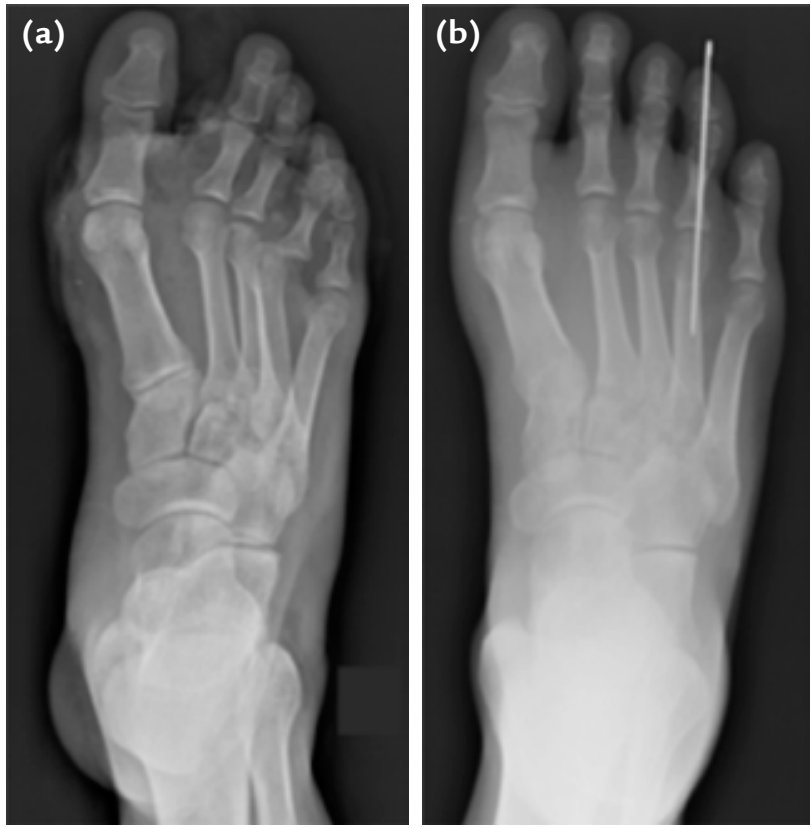

Şekil 6. a, b. 4. MTF eklem çıkığının (a) kapalı redüksiyon sonrası instabil olması nedeniyle hastaya bir adet K-teli ile tespit uygulanmıştır (b). 

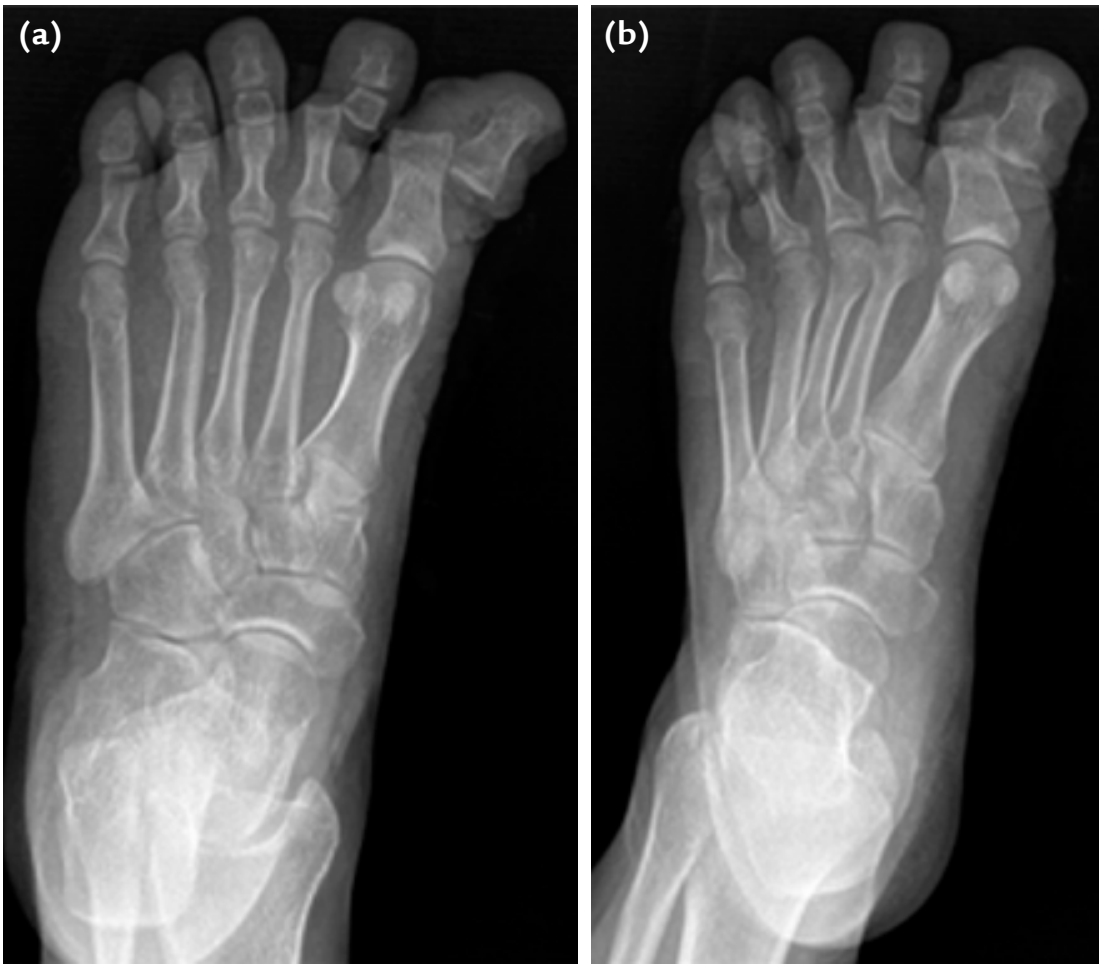

Şekil 7. a, b. Araç içi trafik kazası sonucu 32 yaş erkek hastada gelişen 1 . IF ve 2 . proksimal iF eklem çıkığının AP (a) ve oblik (b) grafileri.

eklem ise 2. parmak proksimal if eklemidir (Şekil 7). Nörovasküler hasar gelişmemesi için erken dönemde redüksiyon uygulanmalıdır. Plantar eklem kapsülü redüksiyona engel olabilir.

\section{DIĞER IZOLE ÇIKIKLAR}

Kalkaneal çıkık, talonaviküler çıkık, naviküla çıkığı, kalkaneoküboid çıkık ve kunoküboid izole çıkıkları, ayağın oldukça nadir görülen yaralanmalarıdır. Diğer çıkıklar gibi, eşlik eden yumuşak doku hasarı ve kırıkların yanı sıra, bunlara doğru tanı konarak stabil bir tespit elde etmek prognoz açısından oldukça önemlidir.

\section{KAYNAKLAR}

1. Wight L, Owen D, Goldbloom D, Knupp M. Pure Ankle Dislocation: A systematic review of the literature and estimation of incidence. Injury 2017;48(10):2027-34. Crossref

2. Garbuio P, Gérard F, Gagneux E. Pure dislocation of the tibiotalar joint. Report of 9 cases [Les luxations tibiotarsiennes pures. À propos de neuf cas]. Rev Chir Orthop $1995 ; 81: 601-8$

3. Rivera F, Bertone C, De Martino M, Pietrobono D, Ghisellini F. Pure dislocation of the ankle: three case reports and literature review. Clin Orthop Relat Res 2001;382:179-84. Crossref
4. Alami M, Bassir R, Mahfoud M, Lamrani MO, Elbardouni A, Berrada MS, El yaacoubi M. Upward tibiotalar dislocation without fracture: A case report. Foot (Edinb) 2010 Dec; 20(4):149-50. Crossref

5. Uyar M, Tan A, Isler M, Cetinus E. Closed posteromedial dislocation of the tibiotalar joint without fracture in a basketball player. Br J Sports Med 2004;38(3):342-3. Crossref

6. Georgilas I, Mouzopoulos G. Anterior ankle dislocation without associated fracture: a case with an 11 year follow-up. Acta Orthop Belg 2008;74(2):266-9.

7. Demiralp B, Komurcu M, Ozturk C, Ozturan K, Tasatan E, Erler K. Acute traumatic open posterolateral dislocation of the ankle without tearing of the tibiofibular syndesmosis ligaments: a case report. J Am Podiatr Med Assoc 2008;98(6):469-72. Crossref

8. Colville M, Colville J, Manoli A. Posteromedial dislocation of the ankle without fracture. J Bone Joint Surg Am 1987;69A(5):706-11. Crossref

9. DeLee JC, Curtis R. Subtalar dislocation of the foot. J Bone Joint Surg Am 1982;64(3):433-7. Crossref

10. Prada-Cañizares A, Auñón-Martín I, Rico JVy, PretellMazzini J. Subtalar dislocation: management and prognosis for an uncommon orthopaedic condition. Int Orthop 2016;40(5):999-1007. Crossref

11. Byrd ZO, Ebraheim M, Weston JT, Liu J, Ebraheim NA. Isolated subtalar dislocation. Orthopedics 2013;36(9):71420. Crossref

12. Rammelt $\mathrm{S}$, Bartoníček J, Park $\mathrm{KH}$. Traumatic Injury to the Subtalar Joint. Foot Ankle Clin 2018;23(3):353-74. Crossref 
13. Pavic R. Talocalcaneal transfixation in total dislocation of the talus and subtalar dislocations. Mil Med 2009;174(3):324-7. Crossref

14. Veltman ES, Steller EJ, Wittich P, Keizer J. Lateral subtalar dislocation. Case report and review of the literature. World J Orthop 2016;7(9):623-7. Crossref

15. Yıldırım Y, Ergün $S$, Akgülle $A H$, Cansü E. Calcaneocuboid joint dislocation: a case report. J Am Podiatr Med Assoc 2014;104(6):644-8. Crossref

16. Main BJ, Jowett RL. Injuries of the midtarsal joint. J Bone Joint Surg $\mathrm{Br}$ 1975;57-B(1):89-97. Crossref

17. Berkowitz MJ, Sanders RW. Dislocations of the Foot. In: Coughlin M, Saltzman C, Anderson RB, editors. Mann's Surgery of the Foot and Ankle, 9th ed. Philadelphia PA: Elsevier Saunders; 2013. pp.1905-72.

18. Hooper G, McMaster MJ. Recurrent bilateral midtarsal subluxations: a case report. J Bone Joint Surg Am 1979;61(4):617-9. Crossref

19. Welck MJ, Zinchenko R, Rudge B. Lisfranc injuries. Injury 2015;46(4):536-41. Crossref

20. Benirschke SK, Meinberg E, Anderson SA, Jones CB, Cole PA. Fractures and dislocations of the midfoot: Lisfranc and Chopart injuries. J Bone Joint Surg Am 2012;94(14):132637. Crossref
21. Yu-Kai Y, Shiu-Bii L. Anatomic parameters of the Lisfranc joint complex in a radiographic and cadaveric comparison. J Foot Ankle Surg 2015;54(5):883-7. Crossref

22. Sivakumar BS, An VVG, Oitment C, Myerson M. Subtle Lisfranc Injuries: A Topical Review and Modification of the Classification System. Orthopedics 2018;41(2):e168-75. Crossref

23. Sandlin MI, Taghavi CE, Charlton TP, Anderson RB. Lisfranc Injuries in the Elite Athlete. Instr Course Lect 2017;66:275-80.

24. Myerson MS, Fisher RT, Burgess AR, Kenzora JE. Fracture dislocations of the tarsometatarsal joints: End results correlated with pathology and treatment. Foot Ankle 1986;6(5):225-42. Crossref

25. Weatherford BM, Anderson JG, Bohay DR. Management of Tarsometatarsal Joint Injuries. J Am Acad Orthop Surg 2017;25(7):469-79. Crossref

26. Calder JD, Whitehouse SL, Saxby TS. Results of isolated Lisfranc injuries and the effect of compensation claims. J Bone Joint Surg Br 2004;86-B(4):527-30. Crossref

27. Zrig M, Othman Y, Bellaaj Z, Koubaa M, Abid A. Dislocation of the First Metatarsophalangeal Joint: A Case Report and Suggested Classification System. J Foot Ankle Surg 2017;56(3):643-7. Crossref 